\title{
Alergia ao glúten: série de nove casos
}

\author{
Gluten allergy: series of nine cases
}

\author{
Estefânia Barrosa Maia', Sónia Lemos², Carla Chaves Loureiro², José António Pinheiro² \\ ${ }^{1}$ Interna de Pediatria do Hospital Pediátrico Carmona da Mota, Centro Hospitalar e Universitário de Coimbra, Coimbra, Portugal; ${ }^{2}$ Clínica de Alergologia Pediátrica, \\ Hospital Pediátrico Carmona da Mota, Centro Hospitalar e Universitário de Coimbra, Coimbra, Portugal.
}

\section{RESUMO}

Objetivos: Havendo poucos casos descritos de alergia ao glúten mediada por IgE, divulgamos uma série de nove casos, com especial relevo sobre o diagnóstico, vias de sensibilização, manifestações clínicas e factores preditivos de prognóstico.

Métodos: Nesta série foram incluídos todos os casos de alergia ao glúten mediada por IgE, seguidos nos últimos 15 anos no ambulatório de Alergologia Pediátrica de um hospital terciário. Foram analisadas idade de início, manifestações iniciais, vias de sensibilização, comorbidades e aquisição de tolerância.

Resultados: Foram incluídas nove crianças com alergia ao glúten, com idades entre 1 e 14 anos, sendo oito meninos. A primeira manifestação ocorreu entre os 5 e 9 meses. Em seis pacientes as primeiras manifestações foram cutâneas, dois apresentaram distúrbios gastrointestinais e uma menina apresentou anafilaxia como manifestação inicial. A via de sensibilização foi cutânea ou por ingestão. O valor de IgE específica para o glúten variou entre 0,73-100 $\mathrm{KU}_{\mathrm{A}} /$. Todas as crianças tinham outra doença atópica. Oito apresentavam alergia alimentar múltipla. Quatro desenvolveram alergia respiratória. Em dois casos ocorreu anafilaxia após o diagnóstico. Três resolveram a alergia ao glúten até os seis anos. Conclusões: A alergia ao glúten é rara, explicando o pequeno número diagnosticado em 15 anos, em um hospital central de referência. Os nove casos tiveram início no primeiro ano de vida, sendo as manifestações cutâneas as mais frequentes. O eczema foi uma apresentação frequente e a sensibilização foi por via cutânea em alguns casos. A alergia alimentar múltipla também foi frequente nos casos descritos. Três das nove crianças resolveram a alergia até os seis anos, tendo em comum uma manifestação inicial cutânea. Nestes nove casos, o valor de IgE específica não foi preditivo da evolução clínica.

DESCRITORES: ALERGIA A GLUTEN; ALERGIA ALIMENTAR; ANAFILAXIA; DERMATITE ATÓPICA.

\section{ABSTRACT}

Aims: With few reported cases of IgE-mediated allergy to gluten, we report a series of nine cases, with special emphasis on diagnosis, process of sensitization, clinical manifestations and predictive factors of prognosis.

Methods: In this series all cases of IgE-mediated allergy to gluten, followed the last 15 years at the Pediatric Allergology of a tertiary hospital, were included. Age of onset, initial symptoms, routes of sensitization, comorbidities and acquisition of tolerance were analyzed.

Results: with gluten allergy, with ages ranging from 1 to 14 years, were included; eight were boys. The first manifestation took place between 5 and 9 months. In six patients the initial symptoms were cutaneous, two patients had gastrointestinal disorders, and one girl showed anaphylaxis as the initial manifestation. The route of sensitization was cutaneous or by food ingestion. Serum specific IgE to gluten ranged from 0,73 to 100KUA/1. All children exhibited other atopic diseases. Eight children had multiple food allergies and four developed respiratory allergy. Two patients suffered anaphylaxis after the diagnosis. Three cases resolved their gluten allergy up to eight years of age.

Conclusions: Gluten allergy is rare, explaining the small number diagnosed in 15 years, in a central referral hospital. The nine cases began in the first year of life, being cutaneous manifestations the most frequent. Eczema is a common presentation and there was dermal sensitization in some cases. Multiple food allergy was also frequent in the cases described. Three of the nine children resolved allergy up to six years, having in common an initial cutaneous manifestation. In these nine cases, the value of specific IgE was not predictive of clinical outcome.

KEY WORDS: GLUTEN ALLERGY; FOOD ALLERGY; ANAPHYLAXIS; ATOPIC DERMATITIS. 


\section{INTRODUÇÃO}

O glúten é uma mistura complexa de polipeptídeos presente nos cereais da família das gramíneas cultivadas (trigo, centeio, aveia e cevada). Consiste em duas frações: uma solúvel em álcool, designada por gliadina, e outra insolúvel em álcool, designada por glutenina (no trigo) e por secalina, avenina e hordeína (respectivamente no centeio, aveia e cevada). ${ }^{1-5}$

O glúten deve ser introduzido na alimentação infantil entre os quatro e seis meses de vida, de forma gradual e de preferência mantendo o aleitamento materno. ${ }^{2,6}$ Habitualmente é introduzido sob forma de farinhas para lactentes, sendo depois consumido em larga escala ao longo da vida. O trigo, o cereal com glúten mais consumido, continua a ser uma das principais fontes alimentares do mundo, contribuindo com $50 \%$ das calorias nos países industrializados e países em desenvolvimento. O consumo global tem aumentado mais rapidamente do que qualquer outro cereal. O trigo encontra-se no grupo dos alimentos que, em conjunto, são responsáveis pela maioria de reacções alérgicas alimentares $(0,4-1 \%)$. ${ }^{1,2,7-9}$

A ingestão de glúten pode desencadear uma resposta imunológica anormal em indivíduos suscetíveis, causando ora doença celíaca (mecanismo não mediado por $\operatorname{IgE}$ ) ora alergia ao glúten (AG) mediada por IgE. ${ }^{2,7,9,10}$ A AG é rara e, como tal, pouco conhecida a sua história natural.

A sintomatologia da AG é variável e semelhante às restantes alergias alimentares. A dermatite atópica é uma manifestação frequente em idade pediátrica, assim como a urticária, estando também relatados casos de angioedema. ${ }^{2-4,7} \mathrm{~A}$ anafilaxia pode surgir em qualquer idade e pode estar associada ao exercício físico após ingestão de cereais (anafilaxia induzida pelo exercício físico), no qual a proteína responsável parece ser a $\omega 5$-gliadina. ${ }^{9-12}$ Podem também surgir manifestações respiratórias (asma e rinite) ou gastrointestinais (vômitos, diarreia, dor abdominal). ${ }^{2-4,7}$

A sensibilização ao glúten ocorre por via oral, através da ingestão de cereais com glúten, por via inalatória, ou por via percutânea pelo contacto com produtos dermatológicos que contêm cereais, como é o caso dos emolientes. ${ }^{2-5}$ A maioria dos indivíduos sensibiliza-se durante o primeiro ano de vida, evoluindo para a tolerância imunológica aos três a cinco anos de idade. ${ }^{3,4}$

A polissensibilização a vários alimentos, tais como, leite, ovo e trigo, ocorre em cerca de $30 \%$ das crianças. Em idade pediátrica, a existência de reatividade cruzada entre cereais e pólenes de gramíneas é baixa., ${ }^{4}$
Como nas restantes alergias alimentares, a investigação alergológica da AG compreende uma história clínica sugestiva, determinação do valor de IgE específica, testes cutâneos e prova de provocação oral. ${ }^{3,7,14}$

$\mathrm{O}$ tratamento da AG baseia-se numa dieta isenta de glúten, isto é, sem trigo, centeio, cevada nem aveia. De diferente modo, na alergia ao trigo, em que a $\omega 5$-gliadina ou outras proteínas exclusivas do trigo estão implicadas, o doente apenas tem de retirar o trigo da dieta. Como alternativa, são propostos outros cereais e farinhas não contendo glúten na sua composição, como arroz, milho e tapioca. ${ }^{1-5,13,15} \mathrm{O}$ alerta para a presença de glúten em emolientes e cosméticos constitui outro ponto-chave do tratamento.

O objectivo deste estudo foi definir melhor a história natural da AG e identificar factores preditivos do diagnóstico.

\section{MÉTODOS}

Foram incluídas todas as crianças e adolescentes com diagnóstico de AG, seguidas no departamento de Alergologia Pediátrica de um hospital de nível terciário, nos últimos 15 anos (1998-2013). Foi definido como diagnóstico de AG: manifestação de doença alérgica imediata após a exposição (ingestão, inalação, contacto cutâneo), IgE específica positiva para glúten e remissão de sintomas após retirada do alérgeno.

Analisaram-se as seguintes variáveis: idade de início dos sintomas, manifestações clínicas, vias de sensibilização, IgE específicas, reacções acidentais, comorbilidades e aquisição de tolerância.

O estudo foi apreciado e aprovado pelo Comitê de Ética para a Saúde do Centro Hospitalar e Universitário de Coimbra, Portugal.

$\mathrm{Na}$ análise de dados foi feita a estatística descritiva com recurso ao programa Microsoft office Excel 2010.

\section{RESULTADOS}

Nove crianças tiveram diagnóstico de $A G$, das quais oito pertencentes ao sexo masculino e com uma mediana de idade atual de quatro anos (1-14 anos). A mediana de idade da primeira manifestação foi seis meses (5-9 meses). Dois terços apresentaram-se inicialmente com manifestações cutâneo-mucosas, dois casos com manifestações gastrointestinais (vômitos/dor abdominal) e um caso apresentou-se com anafilaxia. Dos seis casos com manifestações mucocutâneas, três tiveram apenas urticária, um caso teve urticária e angioedema e dois tiveram exacerbação da dermatite atópica com um emoliente contendo glúten (Tabela 1). 
Tabela 1. Manifestações clínicas iniciais (formas de apresentação) nos nove casos de crianças com alergia ao glúten diagnosticados em um período de 15 anos na Clínica de Alergologia Pediátrica, Hospital Pediátrico Carmona da Mota, Coimbra, Portugal.

\begin{tabular}{|lc}
\hline Manifestações clínicas iniciais & $\begin{array}{c}\text { Número de pacientes } \\
\text { que apresentaram }\end{array}$ \\
\hline Manifestações cutâneo-mucosas & 6 \\
Urticária & 3 \\
Urticária + angioedema & 1 \\
Dermatite atópica & 2 \\
Manifestações gastrointestinais & 2 \\
Vômitos & 1 \\
Dor abdominal & 1 \\
\hline Anafilaxia & 1 \\
\hline
\end{tabular}

Em todas as crianças existia outra doença atópica concomitante: oito doentes com alergia alimentar múltipla (ovo, leite ou peixe), quatro com alergia respiratória (asma e rinite) e sete com eczema atópico. Sete crianças tinham antecedentes familiares de atopia, havendo um caso em que um familiar (mãe) tinha alergia ao trigo, sem especificação de sensibilização às proteínas do trigo, nomeadamente ao glúten.

A sensibilização foi por via cutânea em um caso, que ainda não teria introduzido glúten na alimentação e ocorreu pela aplicação de um emoliente contento glúten. Nos restantes casos a via de sensibilização foi por ingestão. Verificou-se um agravamento do eczema atópico com emolientes contendo glúten em três casos.

A mediana do valor da IgE específica para o glúten foi de 19,1 KU $\mathrm{K}_{\mathrm{A}} / 1\left(0,73-100 \mathrm{KU}_{\mathrm{A}} / 1\right)$. A disparidade dos valores de $\operatorname{IgE}$ específica para glúten não teve correspondência clínica - os doentes com valores mais baixos de IgE específica para glúten $\left(0,7-1,3-1,7 \mathrm{KU}_{\mathrm{A}} / \mathrm{l}\right)$ tiveram manifestações semelhantes aos seus pares: vômitos, urticária e eczema.

Em quatro crianças identificou-se IgE específica positiva para outros cereais que não apresentam glúten na sua composição: quatro positivas para o milho $\left(1,86-9,66 \mathrm{KU}_{\mathrm{A}} / 1\right)$ e uma para o arroz $\left(4,97 \mathrm{KU}_{\mathrm{A}} / 1\right)$. Duas crianças com alergia respiratória apresentaram IgE específica positiva para pólens de gramíneas cultivadas: duas para trigo $\left(2-14,4 \mathrm{KU}_{\mathrm{A}} / 1\right)$, centeio $\left(1,92-12,70 \mathrm{KU}_{\mathrm{A}} / 1\right)$, cevada $\left(2,25-16,2 \mathrm{KU}_{\mathrm{A}} / 1\right)$, aveia $\left(7,77-10,20 \mathrm{KU}_{\mathrm{A}} / 1\right)$ e uma para milho $\left(8,68 \mathrm{KU}_{\mathrm{A}} / 1\right)$ (Tabela 2).

A todas as crianças foi prescrita uma dieta sem glúten e auto-injetor de adrenalina. Durante o seguimento em consulta, seis casos mantiveram a AG, enquanto três resolveram. As seis crianças que mantêm AG têm uma mediana de idade atual de 4,5 anos (2-14 anos) e a mediana de idade da primeira manifestação foi de 6 meses (6-8 meses). Em três crianças a primeira manifestação foi cutâneo-mucosa (um caso de urticária, um caso de urticária com angioedema e um caso de dermatite atópica); apresentação com clínica gastrointestinal em dois casos (um caso de vômitos e um de dor abdominal) e em um caso a anafilaxia foi a primeira manifestação. $\mathrm{O}$ valor mediano de $\mathrm{IgE}$ específica para glúten nestas crianças foi 19,1 KU $/ 1$ (1,3-100 $\left.\mathrm{KU}_{\mathrm{A}} / 1\right)$. Nestes seis casos em que a alergia ao glúten persistiu, a variação de IgE específica para o glúten ao longo do tempo foi variável: em três casos diminuiu e nos restantes três aumentou. Reacções acidentais ocorreram em quatro destas crianças, traduzindo-se em duas por um ou mais episódios de anafilaxia.

Tabela 2. Caraterização clínico-laboratorial dos nove casos de alergia ao glúten.

\begin{tabular}{|c|c|c|c|c|c|c|c|}
\hline & $\begin{array}{l}\text { Idade de início } \\
\text { (meses) }\end{array}$ & $\begin{array}{l}\text { Idade atual } \\
\quad(\text { anos })\end{array}$ & $\begin{array}{l}\text { IgE total } \\
(\mathrm{KU} / \mathrm{I})\end{array}$ & $\begin{array}{l}\text { IgE específica glúten } \\
\left(K U_{A} / I\right)\end{array}$ & $\begin{array}{c}\text { Sensibilização a } \\
\text { outros cereais sem } \\
\text { glúten (alimentares) }\end{array}$ & $\begin{array}{l}\text { Sensibilização a } \\
\text { cereais (inalados) }\end{array}$ & $\begin{array}{l}\text { Outras alergias } \\
\text { alimentares }\end{array}$ \\
\hline Caso 1 & 9 & 8 & 1577 & 100 & - & $\begin{array}{l}\text { trigo, centeio, cevada } \\
\text { e aveia }\end{array}$ & ovo, kiwi e melão \\
\hline Caso 2 & 6 & 2 & 156 & 39,8 & milho & - & ovo \\
\hline Caso 3 & 8 & 4 & 1617 & 100 & milho e arroz & - & ovo e kiwi \\
\hline Caso 4 & 6 & 4 & 377 & 97,8 & milho & - & $\begin{array}{c}\text { ovo, leite de vaca e } \\
\text { peixe }\end{array}$ \\
\hline Caso 5 & 6 & 5 & 959 & 8,2 & - & - & ovo e leite de vaca \\
\hline Caso 6 & 6 & 14 & 177 & 30 & - & $\begin{array}{c}\text { trigo, centeio, } \\
\text { cevada, aveia e milho }\end{array}$ & $\begin{array}{l}\text { ovo, peixe, amendoim } \\
\text { avelã e grão de bico }\end{array}$ \\
\hline Caso 7 & 6 & 7 & 86 & 1,7 & - & - & - \\
\hline Caso 8 & 5 & 1 & 68 & 0,7 & - & - & ovo e leite de vaca \\
\hline Caso 9 & 6 & 2 & 220 & 1,3 & milho & - & leite de vaca \\
\hline
\end{tabular}


Tabela 3. Evolução clínico-laboratorial nos três casos que resolveram a alergia ao glúten.

\begin{tabular}{|c|c|c|c|c|c|c|c|c|}
\hline & $\begin{array}{l}\text { Idade de início } \\
\text { (meses) }\end{array}$ & $\begin{array}{l}\text { Idade de } \\
\text { resolução } \\
\text { (anos) }\end{array}$ & $\begin{array}{l}\text { IgE específica } \\
\text { glúten }\left(K U_{A} / \mathbf{I}\right)\end{array}$ & $\begin{array}{c}\text { Manifestação } \\
\text { inicial }\end{array}$ & Anafilaxia & $\begin{array}{c}\text { Reações } \\
\text { acidentais }\end{array}$ & $\begin{array}{l}\text { Variação de IgE } \\
\text { específica para } \\
\text { glúten }\end{array}$ & $\begin{array}{l}\text { Prova de } \\
\text { provocação oral } \\
\text { ao glúten }\end{array}$ \\
\hline Caso 1 & 9 & 6 & 100 & Urticária & - & Urticária & Diminuiu & Negativa \\
\hline Caso 4 & 6 & 2 & 97,8 & Eczema & - & - & Diminuiu & Negativa \\
\hline Caso 8 & 5 & 1 & 0,7 & Urticária & - & - & Diminuiu & Negativa \\
\hline
\end{tabular}

Três crianças resolveram a AG com idades de 1, 2 e 6 anos (Tabela 3), tendo em comum uma manifestação inicial cutânea (urticária em dois casos e eczema atópico em um caso). A criança que adquiriu tolerância aos seis anos sofreu antes reações acidentais, que se manifestaram por urticária. Em nenhuma ocorreu anafilaxia. Nesses três casos verificou-se diminuição de IgE específica para o glúten ao longo do tempo. A resolução de alergia foi determinada com base na realização de uma prova de provocação oral negativa realizada em meio hospitalar.

\section{DISCUSSÃO}

A AG é uma situação pouco conhecida, mas que pode ser fatal. Sendo o glúten um dos principais componentes do trigo, um dos principais alimentos consumidos e responsável pela maioria das reacções alérgicas alimentares, torna-se importante o conhecimento da história natural de AG. ${ }^{1-3,9}$

O glúten está presente no trigo, no centeio, na aveia e na cevada. Alguns doentes sensibilizaram-se com aveia e não com trigo. O que está em causa não é a alergia à $\omega 5$-gliadina ou outras proteínas exclusivas do trigo, mas sim alergia ao glúten. Assim, a dieta é sobreponível à utilizada na doença celíaca - isenta de glúten. ${ }^{1-5,13,15} \mathrm{O}$ gênero masculino foi largamente predominante nesta série $(8 / 1)$, o que parece demonstrar uma semelhança entre a mesma com outras séries estudadas para alergia ao trigo. ${ }^{8,14}$

Constatamos que a AG surge em idade precoce, tal como esperado (mediana de seis meses). ${ }^{2,6}$ As manifestações cutâneas foram as mais frequentes (urticária) podendo a anafilaxia ser o episódio inaugural. O eczema atópico é uma possível manifestação inicial e a sensibilização pode ocorrer por via cutânea, nomeadamente, por meio de cremes de aveia ou outros produtos dermatológicos contendo glúten. Assim, a exacerbação de um eczema com estes cremes deverá levantar a suspeita de AG.

Todas as crianças com alergia ao glúten apresentaram outras comorbilidades atópicas, nomea- damente, alergia alimentar múltipla (ovo e leite de vaca). Outras séries documentaram a existência de polissensibilização para leite de vaca, ovo e trigo, embora sem explicação fisiopatológica..$^{9,13,14}$ A presença de alergia alimentar múltipla dificulta o estudo da história natural de AG.

Em duas crianças constatou-se existência de sensibilização a outros cereais sem glúten na sua composição (milho e arroz), por provável reactividade cruzada entre proteínas das diferentes espécies de cereais. ${ }^{1}$ De igual modo, a sensibilização a pólens de gramíneas cultivadas, explicaria a polissensibilização ou reactividade cruzada. ${ }^{4,13}$

Dos nove casos estudados, conclui-se que a AG tanto pode ser transitória e resolver na infância (como em três casos desta série), ${ }^{3,4}$ como pode tornar-se persistente (em seis casos), tal como se verifica nas séries estudadas sobre alergia ao trigo. ${ }^{8,13}$ Apesar de constatarmos que a todas as crianças foi prescrito auto-injetor de adrenalina e dieta isenta de glúten, as reações acidentais foram frequentes (cinco casos nesta série) e podem ser graves (dois casos com um ou mais episódios de anafilaxia). Este fato realça a necessidade de um alerta constante para o perigo inerente em qualquer alergia alimentar.

As crianças que não resolveram a AG apresentaram como manifestação inicial reacções mais graves (urticária com angioedema, vômitos, dor abdominal e anafilaxia) e tiveram mais reações acidentais, entre as quais anafilaxia (dois casos).

Nas crianças que resolveram a $\mathrm{AG}$, a clínica de apresentação foi menos grave (urticária ou eczema) e não apresentaram anafilaxia. A IgE específica muito elevada para o glúten não parece ser indicativo de mau prognóstico, visto que as crianças desta série em que houve resolução de alergia apresentavam valores muito variáveis de $\operatorname{IgE}$ especifica para glúten $(0,7$ a $>100 \mathrm{KU}_{\mathrm{A}} / \mathrm{l}$ ). No entanto, o valor da IgE específica para glúten, além de ser importante para o diagnóstico, pode ser útil na monitorização da doença. Salienta-se ainda a importância da realização de provas de provocação oral. 
Conclui-se que a alergia ao glúten é rara, como sugere uma série de 9 casos em 15 anos seguidos em Hospital Central de referência. Todos tiveram início no primeiro ano de vida, sendo as manifestações cutâneas as mais frequentes. $\mathrm{O}$ eczema foi uma apresentação frequente e a sensibilização foi por via cutânea em alguns casos. A alergia alimentar múltipla também foi frequente nos casos descritos. Três das nove crianças resolveram a alergia até os seis anos, tendo em comum uma manifestação inicial cutânea. Nestes nove casos, o valor de IgE específica não foi preditivo da sua evolução clínica.

\section{REFERÊNCIAS}

1. Tathan AS, Shewry PR. Allergens in wheat and related cereals. Clin Exp Allergy. 2008;38(11):1712-26.

2. Hischenhuber C, Crevel R, Jarry B, Mäki M, Moneret-Vautrin DA, Romano A, Troncone R, Ward R. Review article: Safe gluten limits in wheat allergy or coeliac disease. Aliment Pharmacol Ther. 2006;23(5):559-75.

3. Silva AT, Marta CS, Prates S, Morais-Almeida M, Pinto JR. Hipersensibilidade ao trigo: formas de apresentação e proteínas alergénicas. Rev Port Imunoalergol. 2005;13(2):133-40.

4. Inomata N. Wheat allergy. Curr Opin Allergy Clin Immunol. 2009;9(3):238-43.

5. Battais F, Pineau F, Popineau Y, Aparicio C, Kanny G, Guerin L, Moneret-Vautrin DA, Denery-Papini S. Food allergy to wheat: identification of immunoglobulin $\mathrm{E}$ and immunoglobulin G-binding proteins with sequential extracts and purified proteins from wheat flour. Clin Exp Allergy. 2003;33:962-70.

6. Agostoni C, Decsi T, Fewtrell M, Goulet O, Kolacek S, Koletzko B, Michaelsen KF, Moreno L, Puntis J, Rigo J, Shamir R, Szajewska H, Turck D, van Goudoever J; ESPGHAN Committee on Nutrition. Complementary Feeding: a Commentary by the ESPGHAN Committe on Nutrition. J Pediatr Gastroenterol Nutr. 2008;46(1):99-110.

7. Sapone A, Bai JC, Ciacci C, Dolinsek J, Green PH, Hadjivassiliou M, Kaukinen K, Rostami K, Sanders DS, Schumann M, Ullrich R, Villalta D, Volta U, Catassi C, Fasano A. Spectrum of gluten - related disorders: consensus on new nomenclature and classification. BMC Med. 2012;10:13.

8. Keet CA, Matsui EC, Dhillon G, Lenehan P, Paterakis M, Wood RA. The natural history of wheat allergy. Ann Allergy Asthma Immunol. 2009; 102(5):410-5.

9. Leonard MM, Vasagar B. US perspective on gluten-related diseases. Clin Exp Gastroenterol. 2014;7:25-37.

10. Nijeboer P, Bontkes HJ, Mulder CJ, Bouma G. Non-celiac Gluten Sensitivity. Is it in the Gluten or the Grain? J Gastrointestin Liver Dis. 2013;22(4):435-40.

11. Matsuo H, Dahlström J, Tanaka A, Kohno K, Takahashi H, Furumura M, Morita E. Sensitivity and specificity of recombinante $\omega-5$ gliadina - specific IgE measurement for the diagnosis of wheat-dependent exercise-induced anaphylaxis. Allergy. 2008;63(2):233-6.

12. Shewry PR. Wheat. J Exp Bot. 2009;60(6):1537-53.

13. Food Allergy. In: Cantani A, editor. Pediatric Allergy, Asthma and Imunology. New York: Springer; 2008. p. 595-682.

14. Räsänen L, Lehto M, Turjanmaa K, Savolainen J, Reunala T. Allergy to ingested cereals in atopic children. Allergy. 1994;49(10):871-6.

15. Pietzak M. Celiac disease, wheat allergy, and gluten sensitivity: when gluten free is not a fad. J Parenter Enteral Nutr. 2012;36(1): 68S-75S. 